\title{
Indirect Co-Culture with Schwann Cells as a New Approach for Human Endometrial Stem Cells Neural Transdifferentiation
}

\author{
Research Article
}

Terraf $\mathrm{P}^{1}$, Ai $\mathrm{J}^{2 *}$, Kouhsari $\mathrm{SM}^{3}$, Babaloo $\mathrm{H}^{2}$

${ }^{1}$ Department of Cellular and Molecular Biology, School of Biology, University College of Science, University of Tehran, Tehran, Iran.

${ }^{2}$ Department of Tissue Engineering, Faculty of Advanced Medical Technologies, Tehran University of Medical Sciences and Research Center for Science and Technology in Medicine, Tehran University of Medical Sciences, Tehran, Iran.

${ }_{3}^{3}$ Department of Cellular and Molecular Biology, School of Biology, University College of Science, University of Tehran, Tehran, Iran.

\section{Abstract}

\begin{abstract}
Neurodegenerative diseases such as Spinal Cord Injury (SCI) refer to the loss of neuronal cells in the central nervous system. Cell replacement therapy is currently the most propitious approach for the treatment of such diseases. Endometrial Stem Cells (EnSC) due to their unique characteristics have recently gained extensive attention as a new source of mesenchymal-like stem cells for tissue engineering purposes. Research has shown the potency of these cells to differentiate into several cell lineages including osteocytes, adipocytes and neural cells using chemical induction. In this present study we describe how human EnSCs can be induced to differentiate into neuron-like cells when co-cultured with human Schwann cells via insert wells which inhibit intercellular contact of the two cell types. Quantitative gene expression analysis and immunocytochemistry was performed after one week of co-culture. The results confirmed neuronal differentiation of EnSCs which support the notion that Schwann cells produce and secrete neurotrophic factors that can act upon cells without physical contact. Our present findings support the differentiation of EnSCs and the potency of these cells for the treatment of degenerative and acquired disorders of the nervous system.
\end{abstract}

Keywords: Schwann Cells; Human Endometrial Stem Cells; Neural Differentiation; Co-Culture.

\section{Introduction}

Neurodegenerative diseases, characterized by the loss of neuronal cells in the central nervous system result in movement disabilities and loss of function. Spinal cord injury (SCI) refers to damage and loss of neurons in the spinal cord as a result of trauma or disease. On average 375,000 people suffer a SCI each year [1]. Cell replacement is currently the most propitious strategy for the treatment of such neurodegenerative diseases [2]. Although Schwann cells (SC) have demonstrated the most promising effects among cellular grafts, limited availability of autologous donor cells and allograft rejection has prompted a search for a newcell source. Recent progresses in stem cell biology have introduced adult stem cells as a new source for therapeutic strategies [3-5]. Adult stem cells are a unique repertoire of cells that may be obtained from a diverse range of tissues and have the ability to self-renew and differentiate into multiple lineages. However, limited availability, invasive extraction methods and low proliferation capacity have hindered the use of these cells [6]. The uterine endometrium as a dynamic tissue has a distinctive ability to reconstruct through a cyclic regeneration process. Endometrial stem cells (EnSC) are a novel population of mesenchymal-like stem cells found in the endometrium and have a pivotal role in the remarkable regenerative capacity of this tissue $[7,8]$. EnSCs due to the feasibility of isolation, being easily accessible and highly expandable is a unique arsenal of stem cells with in vivo therapeutic activity that may be applied for cell replacement therapy and tissue engineering purposes [6-9]. EnSC have previously demonstrated the ability to

*Corresponding Author:

Jafar Ai

Department of Tissue Engineering, Faculty of Advanced Medical Technologies, Tehran University of Medical Sciences and Research Center for Science and Technology in Medicine,

Tehran University of Medical Sciences, Tehran, Iran.

Tel: +98 (21) 88991118

Fax: +98 (21) 88991117

Email:Jafar_ai@tums.ac.ir

Received: September 06, 2016

Accepted: October 06, 2016

Published: October 14, 2016

Citation: Terraf P, Ai J, Kouhsari SM, Babaloo H (2016) Indirect Co-Culture with Schwann Cells as a New Approach for Human Endometrial Stem Cells Neural Transdifferentia tion. Int J Stem Cell Res Transplant. 04(8), 235-242. doi: http://dx.doi.org/10.19070/2328-3548-1600036

Copyright: Ai $\mathbf{J}^{\circ}$ 2016. This is an open-access article distributed under the terms of the Creative Commons Attribution License, which permits unrestricted use, distribution and reproduction in any medium, provided the original author and source are credited. 
differentiate into multiple lineages including adipocytes, chondrocytes, osteoblasts and neuron-like cells $[6,9,10]$. Neuronal differentiation of EnSCs as a very complex process may be induced by neurotrophins and growth factors $[10,11]$. Supportive cells have the ability to produce and secrete these factors. SCs by providing a supportive environment and promoting neuroprotection and secreting integrins, extracellular matrix molecules and neurotrophic factors are an excellent candidate for this purpose [10, 12]. In our present study in order to inhibit physical contact while deploying the secreted factors by Schwann cells, we have co-cultured human EnSCs and human SCs utilizing insert wells containing polycarbonate membranes. The aim of this study was to scrutinize the neural differentiation ability of human EnSCs in the presence of SC-derived soluble factors.

\section{Materials and Methods}

\section{Tissue Collection and Endometrial Cell Culture}

After obtaining informed consent from patients undergoing surgery for benign gynecological conditions, endometrial biopsies were collected from the fundus of the uterus in accordance with the Tehran University of Medical Sciences ethical committee law. The procedure was performed by a curette in women of reproductive age with an average of 32 years. Attained specimens were washed in Dulbecco's Phosphate Buffered Saline (Sigma, D8537) and cut into 2-3 mm fragments and were dissociated in Hank's Balanced Salt Solution (HBSS; Sigma, USA, H-6136) containing HEPES $(25 \mathrm{mM})$ and Collagenase type $1(1 \mathrm{mg} / \mathrm{mL}$; Sigma, USA, C0130) for $30-45 \mathrm{~min}$ at $37^{\circ} \mathrm{C}$ with agitation. The resulted cell suspension was then passed through a $70 \mu \mathrm{M}$ cell strainer in order to eliminate the glandular epithelial cells and was centrifuged. The mononuclear cells were separated by Ficoll 400 (Sigma, USA, F2637), washed in PBS and finally the isolated cells were cultured in DMEM/F12 (Dulbecco's Modified Eagle Medium/ Nutrient Mixture F12; Sigma, USA, D6421) medium supplemented with 10\% Fetal Bovine Serum (FBS; Gibco, USA, 16000-044), 1\% Penicillin/Streptomycin (Sigma, USA, P4333) and 1\% L-glutamine (Gibco, USA, 25030-024) at $37^{\circ} \mathrm{C}$ and $5 \% \mathrm{CO}_{2}$.

\section{Endometrial Stem Cell Characterization}

Flow Cytometric Analysis: In order to characterize the isolated EnSCs, flow cytometry was performed for cell surface markers. Antibodies used were distinguished into four groups of antimesenchymal, anti-hematopoietic, anti-endothelial and anti-endometrial markers. Mesenchymal markers assessed were CD90 and CD105. Hematopoietic marker was CD34. The endothelial marker was CD31 and the endometrial specific cell surface marker analyzed was CD146. All antibodies were from Santa Cruz.

In Vitro Differentiation of Human EnSCs into Adipocytes: Human EnSCs were plated in cell culture dishes at a concentration of $2 \times 10^{4} \mathrm{cell} / \mathrm{mL}$. After reaching confluency EnSCs were subjected to adipogenic differentiation with induction media consisting of insulin $(10 \mathrm{~g} / \mathrm{mL})$, dexamethasone $(1 \mathrm{M})$, indomethacin $(200 \mathrm{M})$ and isobutylmethylxanthine $(0.5 \mathrm{mM})$ [9]. Cells were cultured in induction media for 10 days and thereafter were stained with Oil Red O (Sigma). Images were obtained by microscopy.

\section{In Vitro Differentiation of Human EnSCs into Osteocytes:}

EnSCs were plated in cell culture dishes at a concentration of $2 \times 10^{4}$ cell $/ \mathrm{mL}$. After reaching confluency cells were exposed to osteogenic induction media consisting of dexamethasone, Lascorbic acid-2-phosphate $(50 \mathrm{mg} / \mathrm{mL})$ and b-glycerophosphate $(10 \mathrm{mM})$ [6]. EnSCs were cultured for 28 days. After the differentiation period cells were stained with Alizarin Red (Sigma).

\section{Isolation and Characterization of Schwann Cells}

In order to extract SCs lower limb tissues containing peripheral nerves were obtained from patients with no sign of neurological abnormalities in accordance with the Tehran University of Medical Sciences ethical committee law. Sciatic nerves were surgically taken out of quadriceps and placed into HBSS supplemented with 1\% Penicillin/Streptomycin and Amphotericin B (25 ng/ mL; Sigma, USA, A2942). After removing the epineurium and connective tissue under a microscopic field the obtained sciatic nerves were minced into 3-4 $\mathrm{mm}$ pieces and dissociated with Dispase(Sigma, USA, P3417) and Collagenase (0.05\%) for 6-8h at $37^{\circ} \mathrm{C}$. The solution and its constituents were then triturated 10 times and incubated overnight at $37^{\circ} \mathrm{C}$ and $5 \% \mathrm{CO}_{2}$. The next day after gentle trituration of the explants the mixture was centrifuged at $1000 \mathrm{rpm}$ for $15 \mathrm{~min}$ and the supernatant was disposed. The cells were re-suspended in DMEM supplemented with 10\% FBS, $2 \mu \mathrm{M}$ Forskolin, 1\% Penicillin/ Streptomycin and Amphotericin B $(25 \mathrm{ng} / \mathrm{mL})$ then cultured on Poly-L-Lysine (Sigma, USA, P4707) coated petri dishes and incubated for 4 days, changing the culture medium every $48 \mathrm{~h}$. After 4 days Cytosine Arabinoside (Ara-C; Sigma, USA, C1768) was added to medium. After three days the medium was replaced with DMEM containing 10\% FBS, 2mM L-Glutamine, Penicillin/ Streptomycin, Amphotericin $\mathrm{B}$ and $2 \mu \mathrm{M}$ Forskolin. The isolated cells were characterized by performing immunocytochemical labeling for S100 and P75 proteins. All animals were provided from Shefa neuroscience animal house and all procedures were performed in accordance with the institutional guidelines of Tehran University of Medical Sciences for animal care and use.

\section{Co-Culturing EnSCs and SCs}

Endometrial stem cells $\left(3 \times 10^{4}\right.$ cells $)$ and Schwann cells $(6 \times 104$ cells) were co-cultured via transwell polycarbonate membrane cell culture inserts (Sigma, USA, CLS3422). The small pore size of the membrane $(8 \mu \mathrm{M})$ highly inhibits the migration of SCs into the lower chamber where the EnSCs are cultured. This system enables SC-derived soluble factors to reach EnSCs without physical contact between the two cell types. These transwell dishes are commonly used to create a cell culture environment that closely resembles the in vivo state. The cells were co-cultured for a period of 7 days in DMEM/F12 medium supplemented with $10 \%$ FBS at $37^{\circ} \mathrm{C}$ and $5 \% \mathrm{CO}_{2}$ before the EnSCs were analyzed for differentiation.

\section{Immunocytochemical Analysis}

After 1 week of co-culture the insert wells were taken out and the EnSCs on the lower chamber were fixed with 4\% Paraformaldehyde (PFA; Sigma, USA, P6148) for $30 \mathrm{~min}$ at room temperature, permeabilized with $0.2 \%$ Triton X-100 (Sigma, USA, T8787) in PBS andimmuno-blocked with 5\% BSA. The cells were 
then treated with primary antibodies for Olig2 mouse monoclonal anti-human 1:200 (Abcam, USA), GFAP mouse monoclonal anti-human 1:200 (Abcam, USA), NF-Hmouse monoclonal anti-human 1:200 (Abcam, USA), and Tuj-1 mouse monoclonal anti-human 1:200 (Abcam, USA) and incubated overnight at $4^{\circ} \mathrm{C}$. After being washed with PBS the next day, cells were incubated at room temperature with secondary antibodies Alexa Fluor 594 donkey anti-mouse IgG 1:500 (Abcam, USA) (for Tuj-1 and NF$\mathrm{H}$ ) and Alexa Fluor 488 donkey anti-mouse IgG 1:500 (Abcam, USA) (for Olig2 and GFAP) for 1 hour. The nuclei were stained with 4', 6-diamidino-2-phenylindole (DAPI; Sigma, USA, D9542) and cells were analyzed (Table 1).

\section{Real-Time Reverse Transcription PCR (RT-PCR) Analysis}

Total RNA was extracted from co-cultured EnSCs using High Pure RNA Isolation Kit (Roche, 11828665001) and to avoid DNA contamination, genomic DNA was eliminated via DNase I from the same kit. Complementary strand DNA was synthesized using Revert Aid First Strand cDNA kit (Thermo Scientific, USA, K1621). Quantitative gene expression was assessed with Real-Time PCR. To this extent the expression levels of Nestin, GFAP, NF-H, Map2 and Olig2 genes were analyzed relative to the housekeeping gene GAPDH. The constituents of each PCR reaction were 1x Power SYBR Green PCR Master Mix (Applied Biosystems, 4368702), $12 \mathrm{ng}$ cDNA and gene specific forward and reverse primers (Table 1) in a total volume of $20 \mu \mathrm{L}$ carried out in a 96 well optical reaction plate using the 7500 Real-Time PCR system (Applied Biosystems, USA). Thermal cycle conditions were the same for all genes with an annealing temperature of $60^{\circ} \mathrm{C}$. The relative quantity of target gene expression was calculated by the comparative $2^{-\Delta \Delta \mathrm{Ct}}$ method. All Ct values were normalized to GAPDH. Gene expression of co-cultured EnSCs were compared to that of undifferentiated EnSCs. See Table 2 for a list of primers used.

\section{Statistical Analysis}

For statistical analysis, Mann-Whitney U test was applied for each two-independent sample. Significant differences were expressed by $\mathrm{p}$ value. All results in this study are presented as Means \pm SD.

\section{Results}

\section{Characterization of Isolated Human Endometrial Stem Cells}

Twenty-four hours post-plating some adherent MSCs appeared in the flask and the cells were heterogeneous in appearance. After 3 passages the EnSCs attained a homogeneous elongated spindleshaped morphology Figure 1a. Flow cytometry results for mesenchymal markers CD90 and CD105 and endometrial marker CD146 were positive. The results were negative for the hematopoietic marker CD34 and the endothelial marker CD31 supporting the fact that the isolated cells were human endometrial cells Figure 2. To confirm that the isolated endometrial-derived stemlike cells were indeed multipotent hEnSCs they were subjected to adipogenic and osteogenic differentiation via induction media.

Table 1. List of Antibodies Used.

\begin{tabular}{|c|c|c|c|}
\hline Antibody name & Description of immunogen & $\begin{array}{c}\text { Manufacturer, host species, catalogue } \\
\text { No., RRID }\end{array}$ & Dilution \\
\hline Anti Olig2 antibody & $\begin{array}{l}\text { Recombinant full length protein correspond- } \\
\text { ing to amino acids 2-78 of human Olig2 }\end{array}$ & $\begin{array}{l}\text { Abcam (USA), Mouse monoclonal IgG2a, } \\
\text { Catalogue No. ab56643, RRID: AB_944547 }\end{array}$ & $1: 200$ \\
\hline $\begin{array}{l}\text { Anti-beta III Tubu- } \\
\text { lin antibody (Tuj1) }\end{array}$ & $\begin{array}{c}\text { Tissue, cells or virus corresponding to Rat } \\
\text { beta III Tubulin }\end{array}$ & $\begin{array}{l}\text { Abcam (USA), Mouse monoclonal IgG2a, } \\
\text { Catalogue No. ab14545, RRID: AB_869994 }\end{array}$ & $1: 200$ \\
\hline $\begin{array}{l}\text { Anti-200 kDneu- } \\
\text { rofilament Heavy } \\
\text { antibody (NF-H) }\end{array}$ & $\begin{array}{l}\text { A pellet of pig brain cold-stable proteins } \\
\text { after depolymerization of microtubules }\end{array}$ & $\begin{array}{l}\text { Abcam (USA), Mouse monoclonal IgG1, } \\
\text { Catalogue No. ab7795, RRID: AB_306084 }\end{array}$ & $1: 200$ \\
\hline $\begin{array}{l}\text { Anti-GFAP anti- } \\
\text { body }\end{array}$ & $\begin{array}{l}\text { This clone has been derived from hybridiza- } \\
\text { tion of } \mathrm{Sp} 2 / 0 \text { myeloma cells with spleen } \\
\text { cells of Balb/c mice immunized with puri- } \\
\text { fied glial fibrillary acidic protein } \\
\text { from human brain }\end{array}$ & $\begin{array}{l}\text { Abcam (USA), Mouse monoclonal IgG2b, } \\
\text { Catalogue No. ab10062, RRID: AB_296804 }\end{array}$ & $1: 200$ \\
\hline $\begin{array}{c}\text { Donkey anti-mouse } \\
\text { IgG H\&L Alexa } \\
\text { Fluor } 594\end{array}$ & $\begin{array}{c}\text { Gamma Immunoglobulins heavy and light } \\
\text { chains }\end{array}$ & $\begin{array}{l}\text { Abcam (USA), Donkey polyclonal IgG, } \\
\text { Catalogue No. ab150108 }\end{array}$ & $1: 500$ \\
\hline $\begin{array}{c}\text { Donkey anti-mouse } \\
\text { IgG H\&L Alexa } \\
\text { Fluor } 488\end{array}$ & $\begin{array}{l}\text { Gamma Immunoglobulins heavy and light } \\
\text { chains }\end{array}$ & $\begin{array}{c}\text { Abcam (USA), Donkey polyclonal IgG, } \\
\text { Catalogue No. ab150105 }\end{array}$ & $1: 500$ \\
\hline Anti-S100 antibody & Purified bovine brain S100 Protein & $\begin{array}{l}\text { Abcam (USA), Mouse monoclonal IgG2a, } \\
\text { Catalogue No. ab4066, RRID: AB_304258 }\end{array}$ & $1: 200$ \\
\hline $\begin{array}{l}\text { Anti-P75 NGF } \\
\text { receptor antibody }\end{array}$ & NGFR from A875 melanoma cells & $\begin{array}{l}\text { Abcam (USA), Mouse monoclonal IgG1, } \\
\text { Catalogue No. ab3125, RRID: AB_303531 }\end{array}$ & $1: 200$ \\
\hline
\end{tabular}


Table 2. List of Primers Used.

\begin{tabular}{|c|c|c|c|}
\hline Genes & Primers & Annealing $\left({ }^{\circ} \mathbf{C}\right)$ & Accession no. \\
\hline Nestin & $\begin{array}{c}\text { F: AGCAGCACTCTTAACTTACG } \\
\text { R: CTGACTTAGCCTATGAGATGG }\end{array}$ & 55 & NM_006617 \\
\hline NF-H & $\begin{array}{c}\text { F: CAGAGCTGGAGGCACTGAAA } \\
\text { R: CTGCTGAATGGCTTCCTGGT }\end{array}$ & 55 & NM_021076 \\
\hline Map-2 & $\begin{array}{c}\text { F: GCTCTGCCTTTAGCAGC } \\
\text { R: GCTTCTCTGACTCCTTTTCC }\end{array}$ & 55.6 & NM_002374.3 \\
\hline Olig2 & $\begin{array}{c}\text { F: CCAGAGCCCGATGACCTTTTT } \\
\text { R: CACTGCCTCCTAGCTTGTCC }\end{array}$ & 60 & NM_005806 \\
\hline GFAP & $\begin{array}{c}\text { F: CCCAGCAACTCCAACTAACAAG } \\
\text { R: TCTCCTTCCTCCTCATTCTAACG }\end{array}$ & 55 & NM_002055 \\
\hline GAPDH & $\begin{array}{r}\text { F: TCGCCAGCCGAGCCA } \\
\text { R: CCTTGACGGTGCCATGGAAT }\end{array}$ & 55 & NM_002046.3 \\
\hline
\end{tabular}

Figure 1. Human Endometrial Stem Cells: (A) Light Microscopy Images of EnSCs Before Co-culture (B),(C) after Co-culturing with Schwann Cells Illustrating Neuronal Morphology and Neurite Outgrowth. Red Arrows Indicate Pyramidal Cell Bodies and Extended Neurite-like Structures that have Interconnected to form Networks.
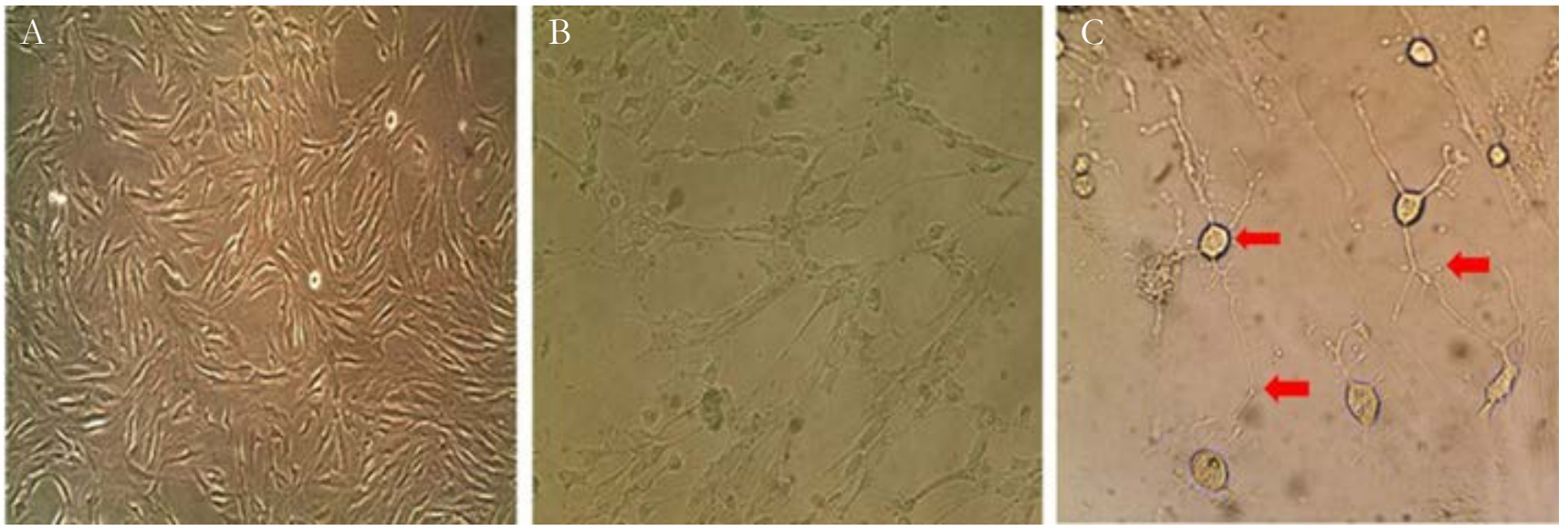

The adipogenic and osteogenic differentiation was confirmed by Oil Red staining and Alizarin Red staining respectively Figure 3.

\section{Characterization of Isolated Human Schwan Cells}

The isolated cells were subjected to immunocytochemical analysis for the Schwann-specific proteins P75 and S100. Results showed the expression of the two proteins and confirmed that isolated cells were indeed human Schwann cells Figure 4.

\section{Characterization of co-cultured human endometrial stem} cells

Morphological studies of neuron-like cells derived from cocultured human EnSCs: One week after co-culturing EnSCs with Schwann cells, a great number of the EnSCs obtained a typical neuronal morphology. Visualized neuron-like cells exhibited typical neuron perikarya morphology with pyramidal and refractile cell bodies. Extended neurite-like structures could be seen that had interconnected into neuronal networks Figure 1b, c.

Immunocytochemical analysis: Immunocytochemical analysis confirmed a correlation between morphological differentiation and immunostaining. Neuron cells are characterized by the positive expression of NF-H (intermediate filament proteins) and Tuj-1 (neuron-specific class III beta tubulin protein). Figure 5 demonstrates the expression of these markers in the neuronallike cells derived from the co-cultured EnSCs Figure 5 a,c whereas native EnSCs showed to be negative Figure 5b, d. The Oligodendrocyte specific marker Olig2 and the Astrocyte specific marker GFAP were not expressed in the differentiated neuron-like cells supporting the absence of oligodendroglial and astroglial differentiation Figure 5 e, g. Thus Schwann cell-derived neurotrophic factors have the ability to induce neuronal differentiation in EnSCs without any physical contact between the two cell types.

Quantitative RNA expression analysis: Real-Time RT-PCR results demonstrated strong correlation with the findings of morphological and immunocytochemical analysis. The neuron-specific markers NF-H and Tuj-1 showed a high increase in expression at the mRNA level while expressions of the Oligodendrocyte and Astrocyte markers Olig2 and GFAP respectively showed a decrease. Nestin a neural precursor cell-specific marker showed a slight increase in expression confirming that a high percent of cocultured EnSCs had indeed differentiated into neuron like-cells and only a small percent of cells was in the precursor state Figure 6. The obtained results further support the notion that neurotrophic factors secreted by Schwann cells can promote the differ- 
Figure 2. Flow Cytometric Analysis: Flow Cytometry Results of Isolated hEnSCs for Mesenchymal Stem Cell Markers (CD90 and CD105), Hematopoietic Marker (CD34), Endothelial Marker (CD31) and Endometrial Stem Cell Marker (CD146). Results are Positive for CD90, CD105 and CD146 and Negative for CD31 and CD34.
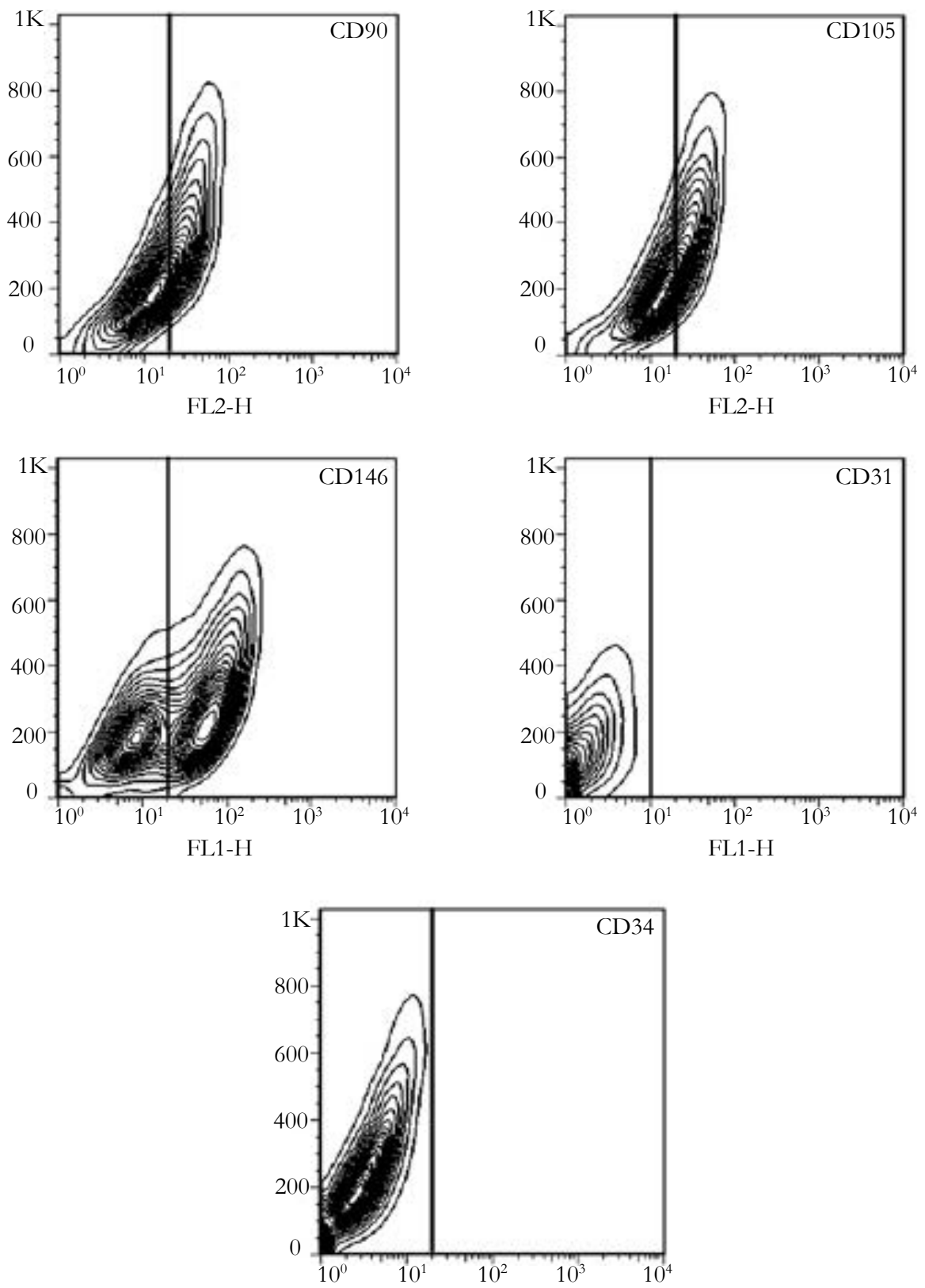

FL3-H

Figure 3. In Vitro Differentiationof Human EnSCs: Human EnSCs Differentiated into (A) Adipocytes Stained with Oil Red and (B) Mineralizing Cells Stained with Alizarin Red
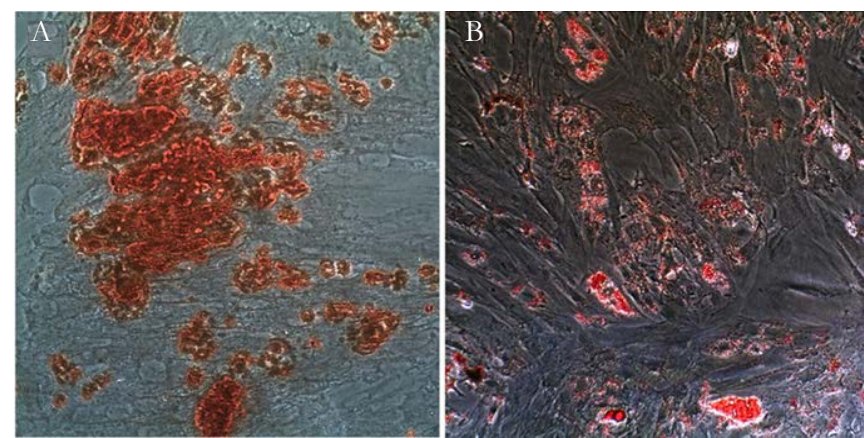
Figure 4. Characterization of Isolated Schwann Cells: (A) Light Microscopy Image of Isolated Schwann cells. (B) Flow Cytometry Analysis of Isolated Schwann Cells for P75 Schwann Cell Marker. (C)Flow Cytometry Analysis of Isolated Schwann Cells for S100 Schwann Cell Marker. Scale Bar $100 \mu \mathrm{m}$.
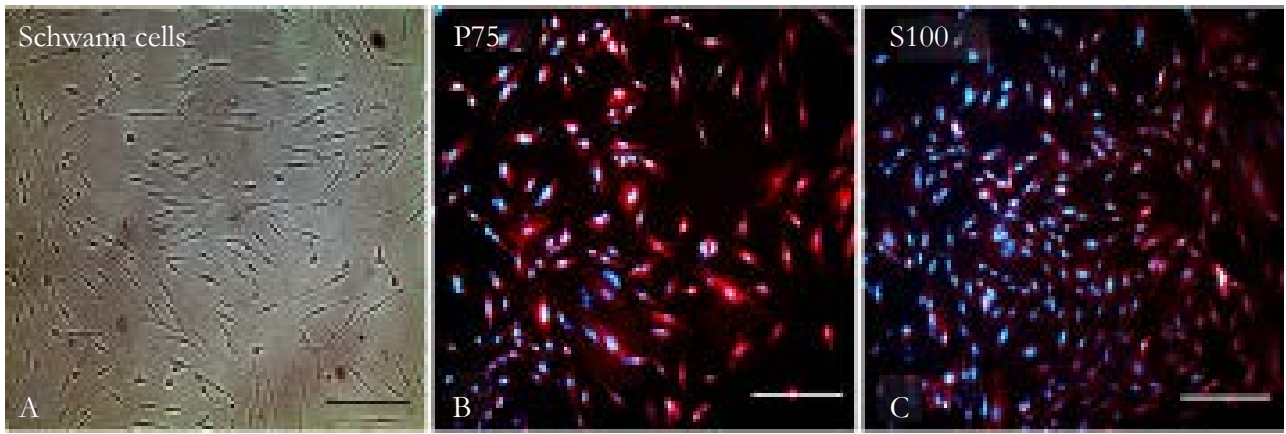

Figure 5. Immunocytochemical Analysis: (A) Positive Staining for NF-H in Co-cultured EnSCs (C) Positive Staining for Tuj-1in Co-cultured EnSCs. (B)(D) Negative Staining for NF-H and Tuj-1 Respectively in Co-cultured EnSCs. (E)(G) Negative Staining for Olig-2 and GFAP Respectively in Control Group. (F)(H) Negative Staining for Olig-2 and GFAP Respectively in Control Group. Scale Bar $100 \mu \mathrm{m}$.
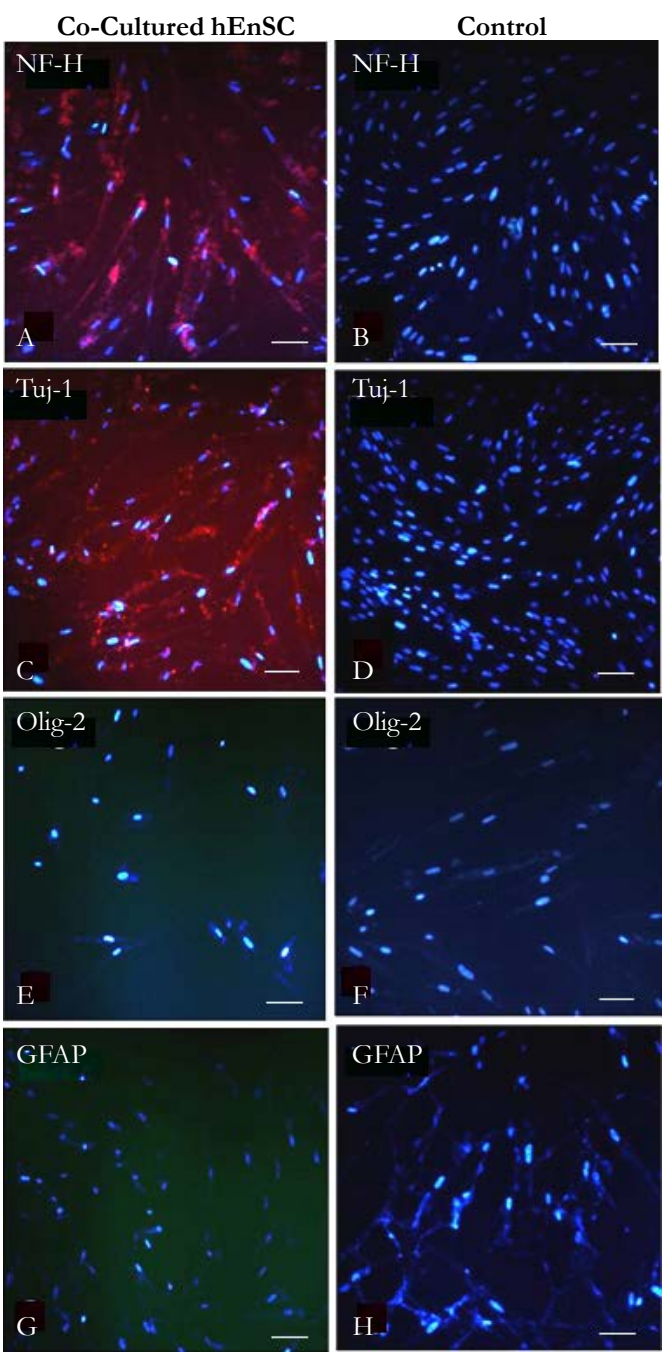

entiation of human endometrial stem cells into neuron-like cells.

\section{Discussion}

In our current study, EnSCs were isolated, characterized and differentiated to neuron like cells by co-culturing with Schwann cells via transwell polycarbonate membrane cell culture inserts. The EnSCs attained neuronal characteristics after 7 days of co-culture. The results from mRNA and protein analysis were concurrent with morphological findings supporting neuronal differentiation. The attained neuron-like cells could express NF-H, Tuj-1 and Nestin as neuronal markers. To further validate the results and confirm that neurotrophic factors secreted by co-cultured Schwann cells are indeed the underlying cause of neural differentiation of EnSCs, EnSCs were cultured in condition media obtained from Schwann cells. The results confirmed that EnSCs when cultured in Schwann cell-derived condition media, differentiated to neuron like cells (data not shown). 
Figure 6. mRNA Expression Analysis: Expression levels of Nestin, Tuj1, NF-H, Olig2 and GFAP Genes were Assessed using Quantitative RT-PCR. Control Groups are Wild type EnSCs; Co-cultured Groups are the EnSCs Co-cultured with Schwann Cells. $\mathrm{n}=3, * \mathrm{P}<0.05, * * \mathrm{P}<0.01$.

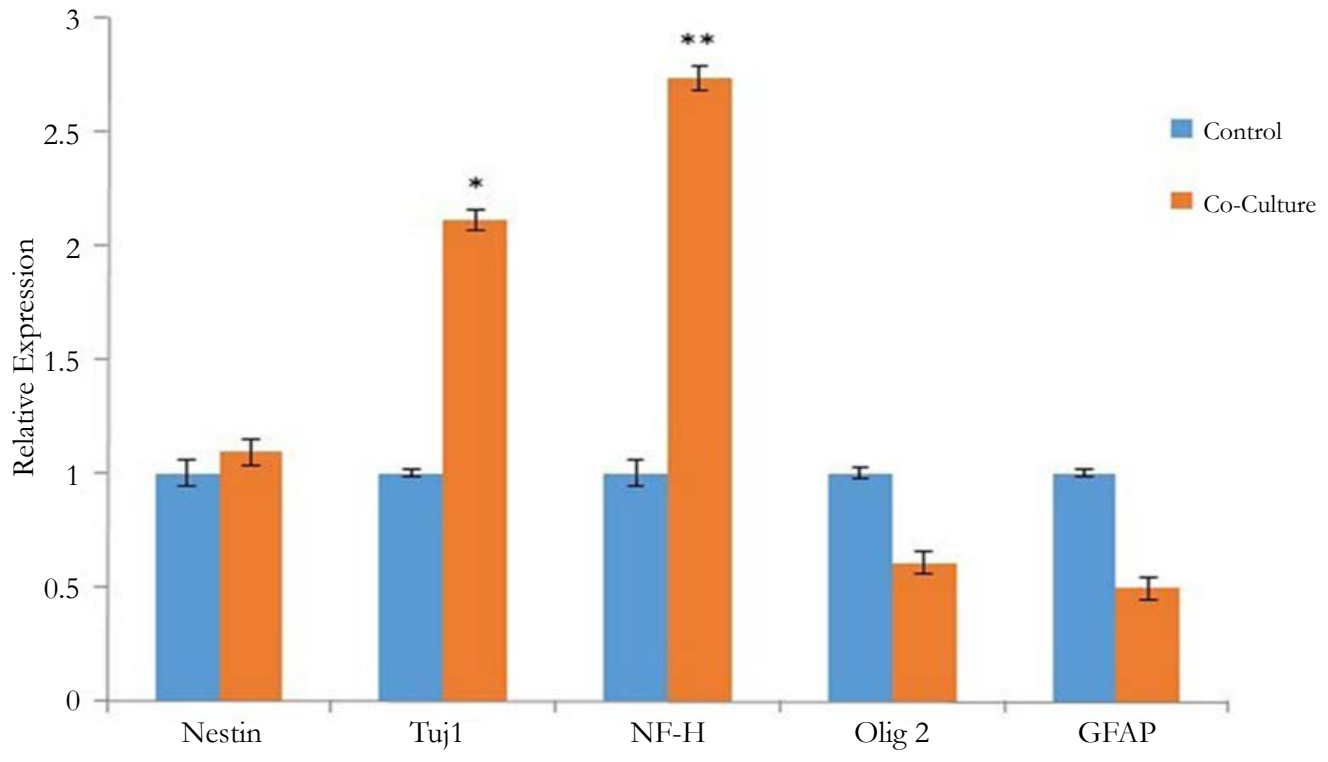

In 2000, for the first time researchers used chemical induction to differentiate BMSCs into a neuronal-like cell [13]. However due to the notion that chemical induction may cause cellular stress which can lead to physical contraction and a neuron-like morphology, later studies suggested combining chemicals with certain growth factors such as BDNF, NGF, PDGF and bFGF to stably differentiate mesenchymal stem cells [14-16]. The complexity of this method and the fact that it was not cost efficient prompted the idea to co-culture BMSCs with Schwann cells to obtain neuronal differentiation [17]. Schwann cells have the ability to produce and secrete neurotropic factors (NTFs), cell adhesion molecules and extracellular matrix proteins such as NGF, BDNF, NT-3, CNTF, GDNF, N-Cad, N-CAM, L1-CAM, integrin, laminin and collagen which are the essential requirements for neuronal differentiation. The possibility of cell fusion as a cause of BMSC neural differentiation led to indirect co-culture of these cells with SCs using transwell culture dishes in order to inhibit intercellular contact [18]. Schwann cells secrete neurotrophic factors, extracellular matrix and cell adhesion molecules and studies have shown that these neurotrophic factors can induce neural differentiation in cocultured BMSCs which can be deployed in cell therapy of neurodegenerative diseases $[17,18]$. However, limitations in using BMSCs such as painful and invasive extraction methods, requirement for anesthesia, losing differentiation capacity in older donors and impure population have prompted attention towards deploying new sources of stem cells. Recent studies have presented EnSCs as a new source of Mesenchymal stem cells $[19,20]$ which exist in the basal layer of the endometrium and display multipotency while maintaining karyotypic normality up to 68 doublings [7]. Previous studies have demonstrated the neural differentiation of EnSCs both with and without Retinoic acid $[6,19]$. The result of our study confirms that neural differentiation of EnSCs can be induced by neurotrophic factors secreted by co-cultured Schwann cells without intercellular contact. These cells are a highly promising source of multipotent stem cells that are abundant, and easily accessible. EnSCs are an attractive alternative for current cell therapy approaches in the treatment of neurodegenerative diseases. We hope that our findings can shed light on future studies of neural regeneration.

\section{References}

[1]. Carvalho KA, Cunha RC, Vialle EN, Osiecki R, Moreira GH, et al., (2008) "Functional Outcome of Bone Marrow Stem Cells (CD45+/CD34-) After Cell Therapy in Acute Spinal Cord Injury: In Exercise Training and in Sedentary Rats". Transplant Proc. 40(3): 847-849.

[2]. Lei Z, Yongda L, Jun M, Yingyu S, Shaoju Z, et al., (2007) "Culture and neural differentiation of rat bone marrow mesenchymal stem cells in vitro”. Cell Biol. Int.31(9): 916-923.

[3]. M Oudega and X-M Xu (2006) "Schwann cell transplantation for repair of the adult spinal cord”. J. Neurotrauma. 23(3-4): 453-467.

[4]. J Sharp and HS Keirstead (2009) "Stem cell-based cell replacement strategies for the central nervous system”. Neurosci Lett. 456(3): 107-111.

[5]. G Martino and S Pluchino (2006) "The therapeutic potential of neural stem cells". Nat Rev Neurosci. 7(5): 395-406.

[6]. ZT Mobarakeh, J Ai, F Yazdani, SMR Sorkhabadi, Z Ghanbari, et al., (2012) "Human endometrial stem cells as a new source for programming to neural cells". Cell Biol Int Rep. 19(1): 7-14.

[7]. CE Gargett, RWS Chan, and KE Schwab (2007) "Endometrial stem cells". Curr Opin Obstet Gynecol. 19(4): 377-383.

[8]. R Dimitrov, T Timeva, D Kyurkchiev, M Stamenova, A Shterev, et al. (2008) "Characterization of clonogenic stromal cells isolated from human endometrium”. Reprod Camb Engl. 135(4): 551-558.

[9]. J Ai, AR Shahverdi, SE Barough, HM Kouchesfehani, S Heidari, et al., (2012) "Derivation of Adipocytes from Human Endometrial Stem Cells (EnSCs)”. J Reprod Infertil. 13(3): 151-157.

[10]. R Villegas, GM Villegas, J Núñez, M Hernández, C Castillo (2005) "Neuron-like differentiation of PC12 cells treated with media conditioned by either sciatic nerves, optic nerves, or Schwann cells”. Cell Mol Neurobiol. 25(2): 451-461.

[11]. GM Villegas, AT Haustein, R Villegas (1995) "Neuronal differentiation of PC12 and chick embryo ganglion cells induced by a sciatic nerve conditioned medium: characterization of the neurotrophic activity". Brain Res. 685(1-2): 77-90.

[12]. LN Novikova, M Brohlin, PJ Kingham, LN Novikov, M Wiberg (2011) "Neuroprotective and growth-promoting effects of bone marrow stromal cells after cervical spinal cord injury in adult rats". Cytotherap. 13(7): 873887.

[13]. D Woodbury, EJ Schwarz, DJ Prockop, IB Black (2000) "Adult rat and human bone marrow stromal cells differentiate into neurons". J Neurosci Res. 61(4): 364-370.

[14]. Y Liu, MS Rao (2003) “Transdifferentiation?fact or artifact”. J Cell Biochem. 88(1): 29-40.

[15]. P Lu, A Blesch, MH Tuszynski (2004) "Induction of bone marrow stromal cells to neurons: differentiation, transdifferentiation, or artifact?". J Neuro- 
sci Res. 77(2): 174-191.

[16]. H Tao, R Rao, DDF Ma (2005) "Cytokine-induced stable neuronal differentiation of human bone marrow mesenchymal stem cells in a serum/feeder cell-free condition". Dev Growth Differ. 47(6): 423-433.

[17]. M Zurita, J Vaquero, S Oya, M Miguel (2005) "Schwann cells induce neuronal differentiation of bone marrow stromal cells". Neuroreport. 16(5): $505-508$.

[18]. M Zurita, J Vaquero, S Oya, C Bonilla, C Aguayo (2007) "Neurotrophic
Schwann-cell factors induce neural differentiation of bone marrow stromal cells". Neuroreport. 18(16): 1713-1717.

[19]. X Meng, TE Ichim, J Zhong, A Rogers, Z Yin, et al., (2007) "Endometrial regenerative cells: A novel stem cell population”. J Transl Med. 5(1): 57.

[20]. CE Gargett, KE Schwab, RM Zillwood, HPT Nguyen, D Wu (2009) "Isolation and Culture of Epithelial Progenitors and Mesenchymal Stem Cells from Human Endometrium”. Biol Reprod. 80(6): 1136-1145. 